\title{
Association between commercial and traditional sugar-sweetened beverages and measures of adiposity in Costa Rica
}

\author{
Jinnie J Rhee ${ }^{1,2,3}$, Josiemer Mattei ${ }^{2}$ and Hannia Campos ${ }^{2,4, *}$ \\ ${ }^{1}$ Department of Epidemiology, Harvard School of Public Health, Boston, MA, USA: ${ }^{2}$ Department of Nutrition, \\ Harvard School of Public Health, 665 Huntington Avenue, Boston, MA 021 15, USA: ${ }^{3}$ Department of Medicine, \\ Brigham and Women's Hospital and Harvard Medical School, Boston, MA, USA: ${ }^{4}$ Centro Centroamericano de \\ Población, Universidad de Costa Rica, San Pedro, Costa Rica
}

Submitted 8 July 2011: Final revision received 2 February 2012: Accepted 21 February 2012: First published online 12 April 2012

\begin{abstract}
Objective: Increasing trends in the consumption of commercial sugar-sweetened beverages (SSB) have occurred in parallel with rising levels of obesity in Latin America, but data showing the relationship between these SSB and obesity are limited. The current study examined the association between commercial and traditional SSB and measures of adiposity in Costa Rica.

Design: A cross-sectional analysis was conducted in which the exposure, SSB intake, was defined as frequency of daily servings of 'fresco' (a traditional homemade beverage), fruit drink (commercially available SSB), soda and fruit juice (made from fruits at home). Multivariate linear regression was used to estimate associations between SSB intake and BMI, waist-to-hip ratio and skinfold thickness.

Setting: Central Valley, Costa Rica.

Subjects: Controls ( $n$ 2045) of a case-control study on diet and heart disease in Costa Rica.

Results: Fresco, fruit drink, soda and fruit juice were consumed $\geq 1$ time/d by $47 \%, 14 \%, 4 \%$ and $14 \%$ of the population, respectively. One serving/d of soda, fruit drink and fresco was associated with $0 \cdot 89,0.49$ and $0 \cdot 21 \mathrm{~kg} / \mathrm{m}^{2}$ higher BMI, respectively (all $P<0 \cdot 05$ ). Fruit drink ( $\geq 1$ serving/d) was associated with higher waist-to-hip ratio $(P=0 \cdot 004)$, while soda and fresco were associated with higher skinfold thickness $(P=0 \cdot 02$ and $0 \cdot 01$, respectively). Associations with fruit juice intake were modest and not statistically significant. Other factors associated with higher BMI were higher income and less education, smoking and physical inactivity (all $P<0 \cdot 05$ ).

Conclusions: Increasing intake of commercially available SSB could be in part responsible for the high prevalence of obesity among Hispanic adults.
\end{abstract}

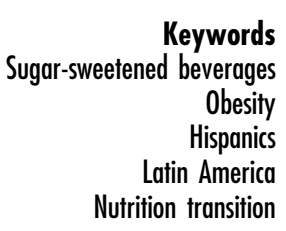

According to the WHO, more than 1 billion adults worldwide are overweight and at least 300 million of them are obese ${ }^{(1)}$. Obesity is associated with numerous diseases, such as insulin resistance, type 2 diabetes, heart disease and obesity-related cancers ${ }^{(2,3)}$; thus, preventing and controlling this metabolic condition has imperative public health impact. While a causal relationship between sugarsweetened beverages (SSB) and obesity remains unclear, numerous studies suggest that increased SSB consumption may lead to weight gain in both adults and children ${ }^{(3,4)}$. One possible explanation is that SSB, especially high intake of energy-dense SSB, increase total energy consumption to a point where it surpasses total energy expenditure ${ }^{(4,5)}$. Additionally, SSB generate low satiety and may encourage individuals to consume more foods per meal, leading to a higher total daily energy intake ${ }^{(6,7)}$. Both mechanisms may ultimately lead to unintentional weight gain.
Ecological data support the aforementioned association between SSB and obesity, as the consumption of SSB has increased in parallel with the escalating prevalence of obesity in many countries ${ }^{(8)}$. For example, in Mexico, the prevalence of obesity among adults has increased dramatically since the late 1980 s, with a $4 \%$ increase from 2000 to $2006^{(9)}$. Concurrently, the percentage of Mexican households consuming soda increased by $22 \%$ from 1989 to $2006^{(10)}$. In Mexico, SSB now contribute approximately 8-9\% of total energy intake, making this country the second largest soda consumer in the world ${ }^{(10)}$.

A similar nutrition transition is taking place rapidly in other Latin American countries where urbanization has led people to become more sedentary while adopting a diet that is high in refined sugars ${ }^{(11,12)}$, heightening the public health concern of a predominantly overweight population ${ }^{(12,13)}$. Indeed, the prevalence of obesity is 
extremely high in Latin American countries ${ }^{(14)}$, including an upward trend observed in Costa Rica. In Costa Rican women aged 20-44 years, the prevalence of overweight and obesity increased steadily from $35 \%$ in 1982 to $46 \%$ in $1996^{(15)}$. By 2009, $60 \%$ of Costa Rican women in this age range were considered overweight ${ }^{(15)}$. A similar trend was observed in men aged 20-64 years, among whom the prevalence of overweight increased from $22 \%$ in 1982 to $62 \%$ in $2009^{(15)}$

Unfortunately, there are limited data on consumption of SSB and any potential relationship with adiposity in Latin American countries. Therefore, we investigated whether SSB consumption is associated with overweight and obesity status using BMI and other anthropometric measurements in Costa Rican adults.

\section{Experimental methods}

\section{Study population}

All data for the present analysis came from control subjects of a population-based case-control study on diet and heart disease conducted in Costa Rica from 1994 to 2004. The details of that study are described elsewhere $^{(16)}$. Controls were randomly selected from the National Census and Statistics Bureau of Costa Rica, and matched with cases of a first acute myocardial infarction for age, sex and area of residence. The study was approved by the Human Subjects Committee of the Harvard School of Public Health and the University of Costa Rica. All participants gave informed consent and the participation rate for controls was $88 \%$.

\section{Data collection}

Trained personnel visited study participants at their homes to collect anthropometric measurements and conduct interviews using closed-ended questions to attain data on sociodemographic characteristics, smoking, physical activity and medical history. Details of the anthropometric measurement collection method are explained elsewhere $^{(17)}$. All anthropometric measurements were taken with participants wearing light clothing and no shoes, collected in duplicate and averaged for analyses. Fieldworkers measured triceps (posterior upper arm, midway between the elbow and acromion), subscapular $(1 \mathrm{~cm}$ below the lower tip of the scapula) and suprailiac (at the midline and above the iliac crest) skinfold thicknesses using Holtain skinfold callipers. All measurements were taken on the right side of the body. Non-stretchable fibreglass or metal tapes were used to measure the waist (smallest horizontal trunk circumference) and hip (largest horizontal circumference around the hip and buttocks) girths. A steel anthropometer and a Detecto bathroom scale or a Seca Alpha Model 770 digital scale accurate to $50 \mathrm{~g}$ were used to measure height and weight, respectively. The two scales were calibrated every other week. BMI was calculated as weight (in kilograms) divided by the square of height (in metres).

Dietary intake was assessed using the semi-quantitative FFQ that was developed and validated specifically for the Costa Rican population ${ }^{(18-21)}$. The following sweetened beverage items were assessed: Coke, Pepsi and other sodas (1 can, $12 \mathrm{oz}$ ); Caffeine Free Coke, Pepsi and other sodas (1 can, $12 \mathrm{oz}$ ); orange juice (1 glass, $8 \mathrm{oz}$ ); other fruit juices ( 1 glass, $8 \mathrm{oz}$ ); commercially available sweetened beverages ( 1 serving, $8 \mathrm{oz}$ ); and 'fresco' ( 1 glass, $8 \mathrm{oz}$ ). Fresco is a popular traditional home-made beverage in Latin America that is often made by blending together fresh fruits, sugar and water. Commercially available sweetened beverages were defined as 'fruit drinks', while natural home-made juices squeezed from various fruits, mainly orange juice $(76 \%)$, were combined into the category 'fruit juice'. The variable 'soda' consisted of all sugar-sweetened soda beverages, which were mostly regular Coke, Pepsi and other colas (84\%), followed by caffeine-free sodas (16\%).

\section{Statistical analysis}

The original population consisted of 2274 participants and $27 \%$ of them were women. Participants with missing data on BMI ( $n$ 25), skinfold thickness ( $n$ 21), SSB consumption ( $n$ 38) and potential confounders ( $n$ 145) were excluded from the present analysis. Thus, a total of 2045 participants ( $90 \%$ of the total studied population) were included. In order to look at the distribution of demographic characteristics, age, which ranged from 18 to 86 years, was categorized into three age groups ( $\leq 44,45-64$ and $\geq 65$ years) and income was categorized into tertiles. All beverage intakes were divided into the following three categories based on the frequency of consumption: never; $>0$ and $<1$ serving/d; and $\geq 1$ serving/d. Differences in group means and in the distribution of continuous and categorical variables were assessed by performing ANOVA and $\chi^{2}$ tests, respectively, using 'never' as the reference category. We did not find significant differences in demographic characteristics between excluded and included participants.

Multivariate regression was used to estimate least square means and $\beta$ coefficients for the association between SSB and continuous markers of adiposity, including BMI, waist-to-hip ratio and subscapular, suprailiac and triceps skinfold thickness. The main model was adjusted for age, sex, education, income, area of residence, smoking and physical activity. Subsequent models considered other food items that have been shown to be associated with SSB consumption: intake of added sugars, dietary fibre intake, alcohol intake, PUFA:SFA intake ratio and, depending on the model, consumption of other SSB other than the main exposure. None of these variables altered the initial model and thus were not included for the final analysis. To determine if total energy intake would mediate the association between SSB and adiposity 
outcomes, we adjusted for total energy intake in a separate model. All $P$ values were two-sided and analyses were performed at the $\alpha=0.05$ level. The SAS statistical software package version $9 \cdot 1$ (SAS Institute Inc., Cary, NC, USA) was used for all statistical analyses.

\section{Results}

The average demographic and anthropometric characteristics, as well as average beverage intakes, are presented by sex and three categories of BMI in Table 1. Men with higher

Table 1 Demographic and anthropometric characteristics and SSB intake by sex and BMI category, men and women aged 18-86 years (n 2045), Costa Rica

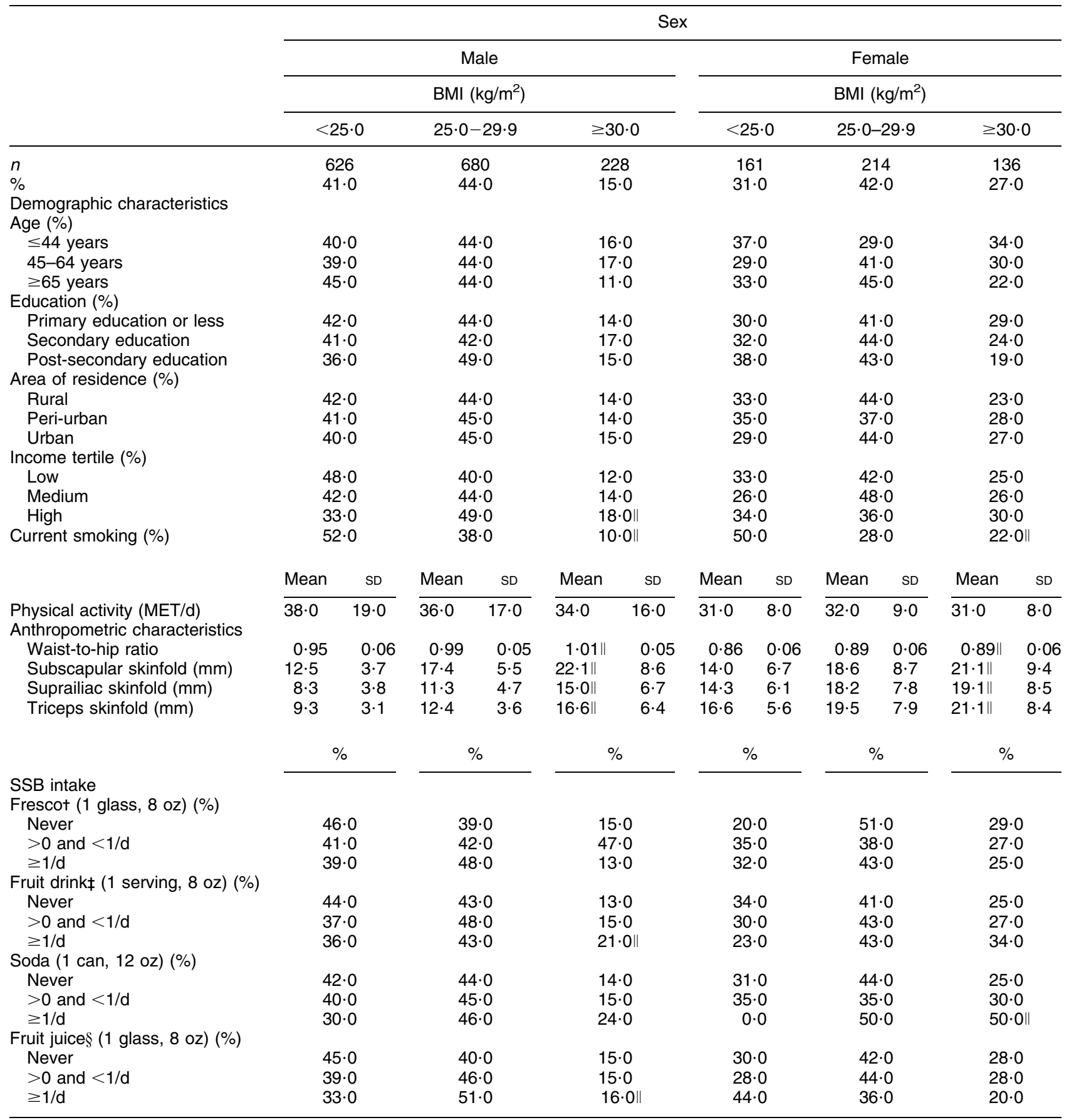

SSB, sugar-sweetened beverage; MET, metabolic equivalents.

tFresco is defined as intake of home-made, non-commercially available, sugar-sweetened fruit beverage.

¥Fruit drink is defined as intake of commercially available SSB.

§Fruit juice is defined as intake of natural orange juice and other fruit juices made at home.

IDifferences in BMI were significant across continuous and categorical variables, as assessed by ANOVA and $\chi^{2}$ tests, respectively: $P<0 \cdot 05$. 
levels of income were more overweight and obese. Current smokers tended to have lower BMI, both males and females. Men who drank fruit drink and fruit juice $\geq 1$ serving/d, and women who drank soda $\geq 1$ serving/d, presented higher frequencies of obesity compared with those who never drank. Fresco, fruit drink, soda and fruit juice were consumed $\geq 1$ time/d by $47 \%, 14 \%, 4 \%$ and $14 \%$ of the population, respectively (data not shown).

We examined general characteristics and potential confounders by frequency of intake of different SSB (Table 2). In general, males and younger participants consumed more SSB. Participants who consumed $\geq 1$ serving fruit juice/d were less physically active than those who did not consume it. Participants who consumed $\geq 1$ serving SSB/d, except for fruit drinks, had higher years of education and income, while those who never consumed SSB had lower energy intake than those who did. Consumption of more fresco and fruit juice but less fruit drink was observed among those residing in urban and peri-urban areas.

Overall, higher consumption of SSB was associated with increased measures of adiposity (Table 3). Increased soda intake was associated with an increase in BMI. Those who consumed $\geq 1$ serving soda/d had $6 \%$ higher mean BMI than never drinkers. Participants who consumed soda $<1$ serving/d and $\geq 1$ serving/d had $2 \%$ and $14 \%$ higher total skinfold thickness, respectively $(P=0 \cdot 02)$, than those who did not consume soda (data not shown). Increased fruit drink intake $<1$ serving/d and $\geq 1$ serving/d was associated with $3 \%$ and $4 \%$ increases in mean BMI, respectively $(P=0 \cdot 007)$. Those who consumed $\geq 1$ serving fruit drink/d had $4 \%$ higher waist-to-hip ratio than never drinkers $(P=0 \cdot 004)$. Subscapular skinfold thickness was higher in those who consumed $\geq 1$ serving fruit juice/d compared with never drinkers $(17 \cdot 3 v \cdot 16 \cdot 1 \mathrm{~mm}, P=0 \cdot 04)$; no other measures of adiposity were significantly associated with fruit juice intake. Those who consumed fresco $<1$ serving/d and $\geq 1$ serving/d had significantly higher mean skinfold thickness at the three measured sites, with total skinfold thickness being $0.5 \mathrm{~mm}$ and $2.6 \mathrm{~mm}$ thicker than for never drinkers $(P=0 \cdot 01$, data not shown). Increased consumption of fresco was not associated with BMI or waist-to-hip ratio. None of the results reported in Table 3 were altered when we adjusted for total energy intake in a separate model.

We also examined the associations between the four different SSB and lifestyle factors, and difference in BMI, adjusted for age and sex (Fig. 1). An increase in soda or fruit drink consumption of 1 serving/d was associated with $0.89 \mathrm{~kg} / \mathrm{m}^{2}$ and $0.49 \mathrm{~kg} / \mathrm{m}^{2}$ higher BMI, respectively $(P=0 \cdot 001$ and $0 \cdot 0005$, respectively). A 1 serving/d increase in fresco consumption was associated with $0.21 \mathrm{~kg} / \mathrm{m}^{2}$ higher $\mathrm{BMI}(P=0 \cdot 04)$. Additional servings of fruit juice were not significantly associated with increases in BMI. An increase in physical activity of $1 \mathrm{sD}(14 \cdot 3 \mathrm{MET}$ (metabolic equivalents)/d) was associated with $0 \cdot 01 \mathrm{~kg} / \mathrm{m}^{2}$ lower BMI.
Education and income were associated with BMI in opposite directions: $1 \mathrm{SD}(5 \cdot 44$ years $)$ increase in education was associated with lower BMI $\left(-0 \cdot 30 \mathrm{~kg} / \mathrm{m}^{2}\right)$, whereas $1 \mathrm{SD}$ (\$US 427/month) increase in income was associated with higher BMI $\left(+0 \cdot 38 \mathrm{~kg} / \mathrm{m}^{2}\right)$. Smoking was significantly associated with lower BMI $\left(-1.54 \mathrm{~kg} / \mathrm{m}^{2}, P<0 \cdot 0001\right)$.

\section{Discussion}

The present analysis shows that increased intake of SSB, especially commercially available SSB such as fruit drinks and soda, is significantly associated with higher measures of adiposity including BMI and waist-to-hip ratio. Stronger associations were found for commercially available SSB (soda and fruit drink) than for traditional fresco or fruit juice. An increase of 1 soda or fruit drink/d was associated with higher BMI. Increasing servings of fresco were also associated with higher BMI, although to a lesser extent. Intake of $\geq 1$ fruit drink or soda/d was also associated with higher waist-to-hip ratio compared with no intake.

Epidemiological data, including evidence from large prospective cohort studies and short-term feeding trials, strongly support the hypothesis that higher intake of SSB is associated with a higher risk of obesity ${ }^{(3,4,22-24)}$. The major findings of our study are consistent with those reports. For example, results from analysis conducted with data of the Nurses' Health Study II showed that an increased intake of SSB over two 4-year periods resulted in the largest amount of weight gain, and an increased intake of fruit punch was also associated with weight gain $^{(23)}$. It has been hypothesized that, in addition to the weight gain due to increased energy intake, other mechanisms could lead to the increased overweight associated with higher SSB intake ${ }^{(3,22)}$. The observed positive associations between SSB intake and increased adiposity after adjusting for total energy in the present study are in agreement with this hypothesis.

Our study findings show that the association between soda and commercially available fruit drinks and obesity is stronger than the association between traditional homemade drinks (fresco) and obesity. This could have important public health implications in Latin American countries where there has been an upward trend in soda consumption. For example in Chile, SSB are one of the top three food items purchased $^{(25)}$, and in Mexico, soda purchases have been increasing from 1984 to $1998^{(26)}$. In our study, only $4 \%$ of the adults consumed $\geq 1$ can of soda/d while $14 \%$ of them consumed $\geq 1$ serving of commercially available fruit drink/d. Although this is a low intake of soda compared with intakes in other Latin American countries, consumption was higher for younger adults, highlighting the importance of targeting programmes that seek to control advertising of soda and other commercially available sweetened beverages towards younger adults to prevent weight gain and obesity at older ages. The potential long-term effects of 
Table 2 Potential confounders by category of SSB intake, men and women aged 18-86 years $(n$ 2045), Costa Rica

\begin{tabular}{|c|c|c|c|c|c|c|c|c|c|c|c|c|c|c|c|c|}
\hline & \multicolumn{4}{|c|}{ Frescot } & \multicolumn{4}{|c|}{ Fruit drinkł } & \multicolumn{4}{|c|}{ Soda } & \multicolumn{4}{|c|}{ Fruit juice§ } \\
\hline & \multicolumn{2}{|c|}{ Never } & \multicolumn{2}{|c|}{$\geq 1 / d$} & \multicolumn{2}{|c|}{ Never } & \multicolumn{2}{|c|}{$\geq 1 / d$} & \multicolumn{2}{|c|}{ Never } & \multicolumn{2}{|c|}{$\geq 1 / d$} & \multicolumn{2}{|c|}{ Never } & \multicolumn{2}{|c|}{$\geq 1 / d$} \\
\hline \multirow[t]{2}{*}{$\begin{array}{l}n \\
\%\end{array}$} & \multicolumn{2}{|c|}{$\begin{array}{l}279 \\
14 \cdot 0\end{array}$} & \multicolumn{2}{|c|}{$\begin{array}{l}968 \\
47 \cdot 0\end{array}$} & \multicolumn{2}{|c|}{$\begin{array}{l}1146 \\
56 \cdot 0\end{array}$} & \multicolumn{2}{|c|}{$\begin{array}{l}283 \\
14 \cdot 0\end{array}$} & \multicolumn{2}{|c|}{$\begin{array}{l}1267 \\
62 \cdot 0\end{array}$} & \multicolumn{2}{|l|}{$\begin{array}{l}84 \\
4 \cdot 0\end{array}$} & \multicolumn{2}{|c|}{$\begin{array}{l}895 \\
44 \cdot 0\end{array}$} & \multicolumn{2}{|c|}{$\begin{array}{l}280 \\
14 \cdot 0\end{array}$} \\
\hline & Mean & SD & Mean & SD & Mean & SD & Mean & SD & Mean & SD & Mean & SD & Mean & SD & Mean & SD \\
\hline $\begin{array}{l}\text { Age (years) } \\
\text { Physical activity (MET/d) } \\
\text { Total energy (kJ) } \\
\text { Total energy (kcal) } \\
\text { Education (years) } \\
\text { Income (\$US/month) }\end{array}$ & $\begin{array}{c}59 \cdot 0 \\
36 \cdot 0 \\
9134 \\
2183 \\
7 \cdot 08 \\
536\end{array}$ & $\begin{array}{c}11 \cdot 0 \\
17 \cdot 0 \\
2824 \\
675 \\
5 \cdot 46 \\
439\end{array}$ & $\begin{array}{c}58 \cdot 0 \| \\
36 \cdot 0 \\
10958 \| \\
2619 \| \\
8 \cdot 02 \| \\
595\end{array}$ & $\begin{array}{c}11 \cdot 0 \\
17 \cdot 0 \\
3284 \\
785 \\
5 \cdot 30 \\
418\end{array}$ & $\begin{array}{c}60 \cdot 0 \\
36 \cdot 0 \\
10004 \\
2391 \\
7 \cdot 73 \\
578\end{array}$ & $\begin{array}{c}11 \cdot 0 \\
16 \cdot 0 \\
3155 \\
754 \\
5 \cdot 53 \\
446\end{array}$ & $\begin{array}{c}55 \cdot 0 \| \\
36 \cdot 0 \\
10983 \| \\
2625 \| \\
7 \cdot 55 \\
567\end{array}$ & $\begin{array}{c}12 \cdot 0 \\
16 \cdot 0 \\
3435 \\
821 \\
4 \cdot 82 \\
388\end{array}$ & $\begin{array}{c}60 \cdot 0 \\
35 \cdot 0 \\
9841 \\
2352 \\
7 \cdot 57 \\
553\end{array}$ & $\begin{array}{c}11 \cdot 0 \\
15 \cdot 0 \\
2954 \\
706 \\
5 \cdot 49 \\
422\end{array}$ & $\begin{array}{c}53 \cdot 0 \| \\
39 \cdot 0 \\
12816 \| \\
3063 \| \\
9 \cdot 74 \| \\
621 \|\end{array}$ & $\begin{array}{c}12 \cdot 0 \\
23 \cdot 0 \\
3791 \\
906 \\
5 \cdot 33 \\
414\end{array}$ & $\begin{array}{c}60 \cdot 0 \\
36 \cdot 0 \\
9770 \\
2335 \\
6 \cdot 27 \\
467\end{array}$ & $\begin{array}{c}11 \cdot 0 \\
18 \cdot 0 \\
3050 \\
729 \\
4 \cdot 72 \\
366\end{array}$ & $\begin{array}{r}59 \cdot 0 \| \\
33.0 \| \\
11000 \| \\
2629 \| \\
10 \cdot 5 \| \\
802 \|\end{array}$ & $\begin{array}{c}11 \cdot 0 \\
12 \cdot 0 \\
3343 \\
799 \\
5 \cdot 91 \\
507\end{array}$ \\
\hline Income (\$US/month) & \multicolumn{2}{|c|}{$\%$} & \multicolumn{2}{|l|}{$\%$} & \multicolumn{2}{|c|}{$\%$} & \multicolumn{2}{|c|}{$\%$} & \multicolumn{2}{|c|}{$\%$} & \multicolumn{2}{|l|}{$\%$} & \multicolumn{2}{|c|}{$\%$} & \multicolumn{2}{|c|}{$\%$} \\
\hline \multicolumn{17}{|l|}{ Sex } \\
\hline $\begin{array}{l}\text { Male } \\
\text { Female }\end{array}$ & \multicolumn{2}{|c|}{$\begin{array}{l}13 \cdot 4 \\
14 \cdot 3\end{array}$} & \multicolumn{2}{|c|}{$48 \cdot 2$} & \multicolumn{2}{|c|}{$54 \cdot 8$} & \multicolumn{2}{|c|}{$\begin{array}{l}14 \cdot 8 \\
11 \cdot 0 \|\end{array}$} & \multicolumn{2}{|c|}{$\begin{array}{l}58 \cdot 8 \\
71 \cdot 4\end{array}$} & $\begin{array}{l}4 \cdot 8 \\
2 \cdot 0 \|\end{array}$ & & $\begin{array}{l}42 \\
47\end{array}$ & $\cdot 6$ & $\begin{array}{l}13 . \\
14 .\end{array}$ & \\
\hline Area of residence (\%) & & & & & & & & & & & & & & & & \\
\hline $\begin{array}{l}\text { Rural } \\
\text { Peri-urban } \\
\text { Urban } \\
\text { Current smoking (\%) }\end{array}$ & $\begin{array}{l}18 \\
13 \\
11 \\
16\end{array}$ & & $\begin{array}{l}46 \cdot 6 \\
47 \cdot 1 \\
47 \cdot 9 \\
46 \cdot 4\end{array}$ & & $\begin{array}{l}54 . \\
54 . \\
59 . \\
54 .\end{array}$ & & $\begin{array}{l}16 . \\
12 \\
13 \cdot \\
16 .\end{array}$ & & $\begin{array}{l}64 \\
60 \\
61 \\
57\end{array}$ & $\begin{array}{l}1 \cdot 6 \\
\cdot 8 \\
\cdot 3 \\
7.1\end{array}$ & $\begin{array}{l}4 \cdot 4 \\
4 \cdot 1 \\
4 \cdot 0 \\
3 \cdot 9\end{array}$ & & $\begin{array}{l}49 \\
39 \\
41 \\
48\end{array}$ & $\begin{array}{l}\cdot 2 \\
\cdot 3 \\
\cdot 3 \\
\cdot 6\end{array}$ & $\begin{array}{l}11 . \\
12 . \\
16 . \\
11 .\end{array}$ & \\
\hline
\end{tabular}

SSB, sugar-sweetened beverage; MET, metabolic equivalents.

+ Fresco is defined as intake of home-made, non-commercially available, sugar-sweetened fruit beverage.

¥ Fruit drink is defined as intake of commercially available SSB.

\& Fruit juice is defined as intake of natural orange juice and other fruit juices made at home.
$\|$ Values were significantly different from those of the reference group ('never'), as assessed by ANOVA and $\chi^{2}$ tests for continuous and categorical variables, respectively: $P<0 \cdot 05$. 
Table 3 Adjusted mean adiposity measurements by category of SSB intake, men and women aged 18-86 years ( $n$ 2045), Costa Rica

\begin{tabular}{|c|c|c|c|c|c|}
\hline & \multirow[b]{2}{*}{ BMI $\left(\mathrm{kg} / \mathrm{m}^{2}\right)$} & \multirow[b]{2}{*}{ Waist-to-hip ratio } & \multicolumn{3}{|c|}{ Skinfold thicknesst } \\
\hline & & & Subscapular (mm) & Suprailiac (mm) & Triceps (mm) \\
\hline \multicolumn{6}{|l|}{ Fresco $\ddagger$} \\
\hline Never ( $n$ 279) & $26 \cdot 2$ & 0.92 & $16 \cdot 2$ & $13 \cdot 0$ & $14 \cdot 6$ \\
\hline$>0$ and $<1 / \mathrm{d}(n 798)$ & $26 \cdot 1$ & 0.92 & $16 \cdot 1$ & $13 \cdot 2$ & $15 \cdot 0$ \\
\hline$\geq 1 / \mathrm{d}(n 968)$ & $26 \cdot 2$ & 0.92 & $16 \cdot 9+t$ & $13 \cdot 9 \cdot, t+$ & $15 \cdot 5$ ๑ \\
\hline$P$ value & $0 \cdot 82$ & 0.29 & 0.03 & 0.01 & 0.02 \\
\hline \multicolumn{6}{|l|}{ Fruit drink§ } \\
\hline Never ( $n$ 1146) & $26 \cdot 0$ & 0.90 & $16 \cdot 6$ & $13 \cdot 6$ & $15 \cdot 3$ \\
\hline$>0$ and $<1 / \mathrm{d}(n 616)$ & $26 \cdot 8$ & 0.93 & $15 \cdot 8$ & $13 \cdot 3$ & $14 \cdot 7$ \\
\hline$\geq 1 / \mathrm{d}(n 283)$ & $27 \cdot 19$ & $0.94 \uparrow$ & $16 \cdot 1$ & $13 \cdot 1$ & $14 \cdot 6$ \\
\hline$P$ value & 0.007 & 0.004 & $0 \cdot 24$ & 0.50 & 0.09 \\
\hline \multicolumn{6}{|l|}{ Soda } \\
\hline Never ( $n$ 1267) & $26 \cdot 1$ & 0.92 & $16 \cdot 3$ & $13 \cdot 3$ & $15 \cdot 0$ \\
\hline$>0$ and $<1 / \mathrm{d}$ (n 694) & $26 \cdot 0$ & 0.92 & $16 \cdot 7$ & $13 \cdot 7$ & $15 \cdot 4$ \\
\hline$\geq 1 / \mathrm{d}(n 84)$ & $27 \cdot 7 \cdot,+t$ & 0.939 & $18 \cdot 8 \uparrow, t \dagger$ & $15 \cdot 3 \cdot, t+$ & $16 \cdot 6$ ฯ \\
\hline$P$ value & 0.005 & $0 \cdot 10$ & 0.03 & 0.03 & 0.05 \\
\hline \multicolumn{6}{|l|}{ Fruit juicell } \\
\hline Never $(n 895)$ & $26 \cdot 0$ & 0.92 & $16 \cdot 1$ & $13 \cdot 3$ & $15 \cdot 1$ \\
\hline$>0$ and $<1 / d(n 870)$ & $26 \cdot 2$ & 0.92 & $16 \cdot 5$ & $13 \cdot 6$ & $15 \cdot 0$ \\
\hline$\geq 1 / \mathrm{d}(n 280)$ & $26 \cdot 3$ & 0.92 & $17 \cdot 3$ & $13 \cdot 9$ & $15 \cdot 7$ \\
\hline$P$ value & $0 \cdot 50$ & $0 \cdot 30$ & 0.04 & $0 \cdot 30$ & $0 \cdot 19$ \\
\hline
\end{tabular}

SSB, sugar-sweetened beverage.

tMeans are adjusted for age, sex, education, income, area of residence, smoking and physical activity.

$\ddagger$ Fresco is defined as intake of home-made, non-commercially available, sugar-sweetened fruit beverage.

§Fruit drink is defined as intake of commercially available SSB.

$\|$ Fruit juice is defined as intake of orange juice and other fruit juices made at home.

-Mean values were significantly different from those of the never category: $P<0.05$.

t+Mean values were significantly different from those of the $>0$ and $<1 /$ d category: $P<0.05$.

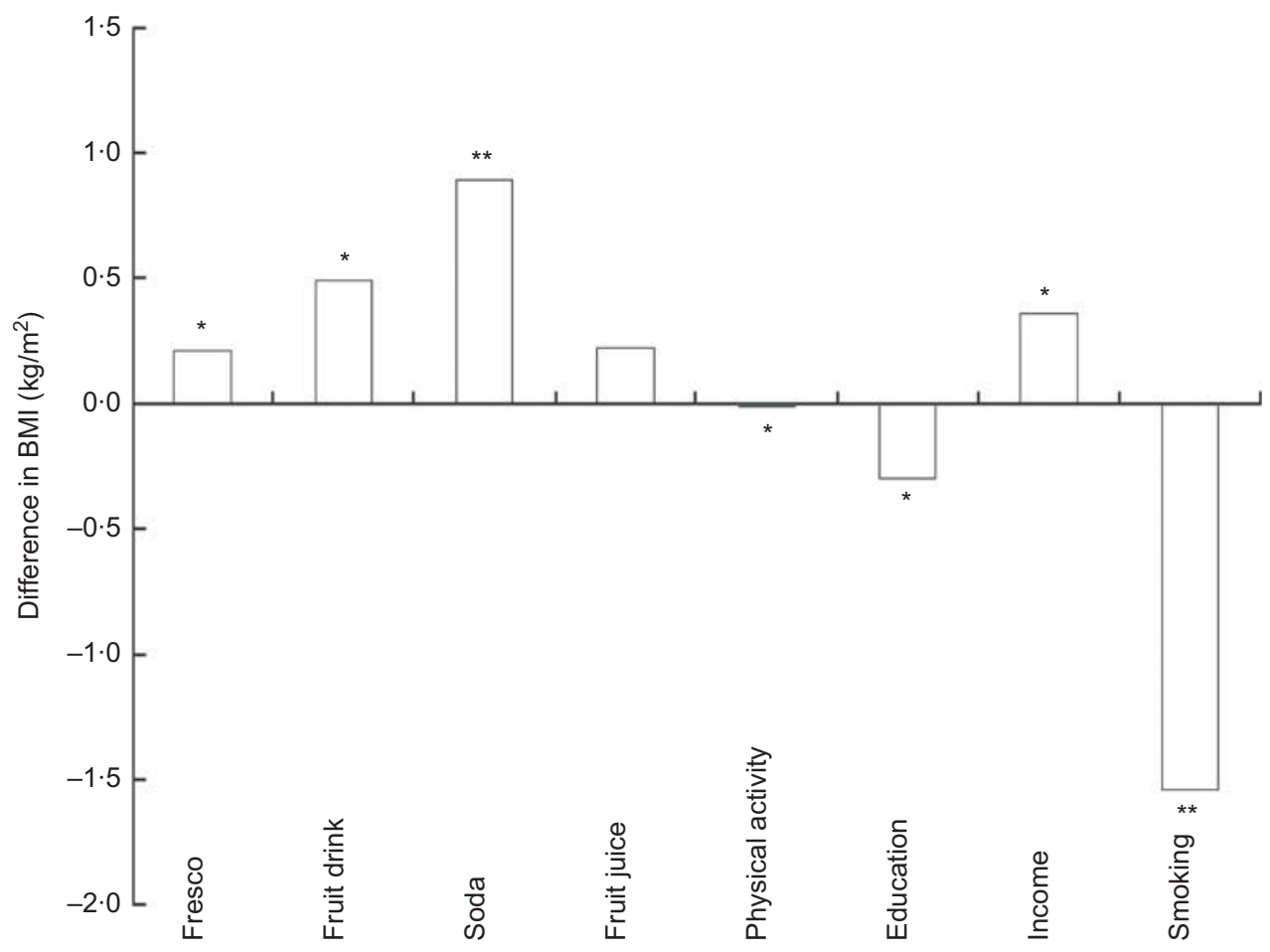

Fig. 1 Differences in BMI $\left(\mathrm{kg} / \mathrm{m}^{2}\right)$ for varying units of intake of sugar-sweetened beverages and lifestyle factors, men and women aged 18-86 years ( $n$ 2045), Costa Rica. The units for each exposure variable and lifestyle factor are as follows: fresco: an increase of 1 glass $/ \mathrm{d}$ ( $8 \mathrm{oz})$; fruit drink: an increase of 1 serving/d $(8 \mathrm{oz})$; soda: an increase of $1 \mathrm{can} / \mathrm{d}$ (12 oz); fruit juice: an increase of 1 glass/d (8 oz); physical activity: an increase of $1 \mathrm{SD}$ (14.3 MET (metabolic equivalents)/d); education: an increase of $1 \mathrm{SD}(5 \cdot 44$ years); income: an increase of 1 SD (\$US 427/month); and smoking. The model was adjusted for age, sex and total energy intake. All $P$ values were significant at the $\alpha=0.05$ level except for fruit juice. ${ }^{*} P<0.05 ;{ }^{\star *} P \leq 0.0001$ 
fresco consumption on overweight and obesity in the Costa Rican population should not be ignored. Although the association between increased servings of fresco and BMI was not as strong as that between increased servings of soda and BMI, a higher percentage of our participants consumed fresco (47\%) compared with soda (4\%). As such, the potential impact of fresco on health should be examined further and be addressed in Costa Rican dietary recommendations in the future.

Based on earlier findings, it has been hypothesized that the burden of obesity shifts to disadvantaged groups with lower socio-economic status, especially in low-income countries ${ }^{(27-29)}$. CARMELA, a cross-sectional, populationbased observational study done in seven major Latin American cities, supported this hypothesis by showing an inverse gradient between socio-economic status and BMI, waist circumference and metabolic syndrome in women ${ }^{(27)}$. In a recent trend study published by Singh et $a l^{(29)}$, higher obesity prevalence was observed in immigrants in the USA with lower education, income and occupation levels in each time period examined, but over time higher socio-economic groups experienced more rapid increases in prevalence. In our study, higher income was associated with higher BMI. Overweight and obesity prevalence has been increasing rapidly in Latin America, and this emerging problem could partially be explained by rapid socio-economic development and urbanization and adoption of Western diet patterns and sedentary behaviours ${ }^{(30)}$. For developing countries, a higher socio-economic level may allow individuals to afford 'Western' foods and beverages, including commercial $\mathrm{SSB}$, which tend to be more costly than the traditional drinks ${ }^{(31)}$. Such findings render support to the notion that improved socio-economic status and lifestyles are associated with an increased risk of obesity ${ }^{(28,30,32)}$. Opposite to the results for income, we observed that higher education was associated with lower BMI. While a report showed that education has a minimal effect on obesity among foreignborn Hispanics living in the USA ${ }^{(33)}$, intake of added sugar has been inversely associated with educational attainment in US Hispanic men ${ }^{(34)}$. Although education and income tend to be linked, higher education may counterbalance the association between high income and obesity, as individuals become well informed about health and diet in general. Therefore, considerations should be given to obesity prevention measures that seek to improve education along with socio-economic progress in Latin American countries.

A major strength of the present study is the separate analysis of commercially prepared and home-made traditional beverages rather than a combined analysis. This allowed us to determine differences in association with adiposity by type of beverage and provide targeted recommendations on limiting intake of specific types of beverages. The study also benefited from a large sample size, high participation rate and the use of detailed dietary assessment using the standardized FFQ designed and validated specifically for Costa Ricans. A main limitation of the study is its cross-sectional design, which cannot establish directionality of the association. Our study results may be applicable only to other Hispanic ethnic groups with similar patterns of beverage consumption. As there are scarce data on such dietary preferences among Hispanics $^{(14)}$, our study is a major contribution to such body of work and encourages future epidemiological research in this field, particularly in Latin America.

\section{Conclusions}

Increased intake of commercially available SSB could partly explain the increasing prevalence of obesity in Latin America. Whether preventing SSB consumption will stop or diminish levels of obesity warrants further examination, but our results are consistent with other study findings and possible biological mechanisms that could explain weight gain from increased intake of SSB. Because obesity and overweight are major risk factors for various chronic diseases, it is important to establish dietary recommendations that can raise public awareness on the potential health risks of high consumption of SSB.

\section{Acknowledgements}

This study was supported by grants HL49086, HL60692 and AG00158 from the National Institutes of Health. There is no conflict of interest to declare. All authors had full access to all data in the study and take responsibility for the integrity of the data and the accuracy of data analysis. All authors have participated sufficiently in the work to take public responsibility for the whole manuscript. J.J.R. conducted statistical analysis, interpreted the results and wrote the manuscript. J.M. and H.C. contributed to the data analysis and interpretation, and provided critical revision of the manuscript. H.C. conceptualized and designed the study.

\section{References}

1. World Health Organization (2003) Obesity and overweight fact sheet. http://www.who.int/dietphysicalactivity/media/ en/gsfs_obesity.pdf (accessed May 2011).

2. Dixon JB (2010) The effect of obesity on health outcomes. Mol Cell Endocrinol 316, 104-108.

3. Malik VS, Schulze MB \& Hu FB (2006) Intake of sugarsweetened beverages and weight gain: a systematic review. Am J Clin Nutr 84, 274-288.

4. Vartanian LR, Schwartz MB \& Brownell KD (2007) Effects of soft drink consumption on nutrition and health: a systematic review and meta-analysis. Am J Public Health 97, 667-675.

5. Bachman CM, Baranowski T \& Nicklas TA (2006) Is there an association between sweetened beverages and adiposity? Nutr Rev 64, 153-174.

6. Almiron-Roig E, Chen Y \& Drewnowski A (2003) Liquid calories and the failure of satiety: how good is the evidence? Obes Rev 4, 201-212. 
7. Johnson RK, Appel LJ, Brands M et al. (2009) Dietary sugars intake and cardiovascular health: a scientific statement from the American Heart Association. Circulation 120, 1011-1020.

8. Drewnowski A \& Bellisle F (2007) Liquid calories, sugar, and body weight. Am J Clin Nutr 85, 651-661.

9. Ford ES \& Mokdad AH (2008) Epidemiology of obesity in the Western hemisphere. J Clin Endocrinol Metab 93, 11 Suppl. 1, S1-S8.

10. Vergara-Castaneda A, Castillo-Martinez L, Colin-Ramirez E et al. (2010) Overweight, obesity, high blood pressure and lifestyle factors among Mexican children and their parents. Environ Health Prev Med 15, 358-366.

11. Kain J, Vio F \& Albala C (2003) Obesity trends and determinant factors in Latin America. Cad Saude Publica 19, Suppl. 1, S77-S86.

12. Popkin BM (2001) The nutrition transition and obesity in the developing world. $J$ Nutr 131, issue 3, 871S-873S.

13. Popkin BM \& Doak CM (1998) The obesity epidemic is a worldwide phenomenon. Nutr Rev 56, 106-114.

14. Filozof C, Gonzalez C, Sereday M et al. (2001) Obesity prevalence and trends in Latin-American countries. Obes Rev 2, 99-106.

15. Avila Aguero ML (2009) Encuesta Nacional De Nutricion, Costa Rica, 2008-2009. Internet: http://www.ministeriodesalud.go.cr/ index.php/menu-principal-proyectos-y-propuestas-ms/doc view/33-encuesta-nacional-de-nutricion-costa-rica-2008-2009 (accessed May 2011).

16. Colon-Ramos U, Kabagambe EK, Baylin A et al. (2007) Socio-economic status and health awareness are associated with choice of cooking oil in Costa Rica. Public Health Nutr 10, 1214-1222.

17. Campos H, Bailey SM, Gussak LS et al. (1991) Relations of body habitus, fitness level, and cardiovascular risk factors including lipoproteins and apolipoproteins in a rural and urban Costa Rican population. Arterioscler Thromb 11, 1077-1088.

18. Baylin A, Kabagambe EK, Siles X et al. (2002) Adipose tissue biomarkers of fatty acid intake. Am J Clin Nutr 76, 750-757.

19. El-Sohemy A, Baylin A, Ascherio A et al. (2001) Populationbased study of $\alpha$ - and $\gamma$-tocopherol in plasma and adipose tissue as biomarkers of intake in Costa Rican adults. $A m J$ Clin Nutr 74, 356-363.

20. El-Sohemy A, Baylin A, Kabagambe E et al. (2002) Individual carotenoid concentrations in adipose tissue and plasma as biomarkers of dietary intake. Am J Clin Nutr 76, 172-179.

21. Kabagambe EK, Baylin A, Siles X et al. (2003) Individual saturated fatty acids and nonfatal acute myocardial infarction in Costa Rica. Eur J Clin Nutr 57, 1447-1457.
22. Malik VS, Popkin BM, Bray GA et al. (2010) Sugarsweetened beverages, obesity, type 2 diabetes mellitus, and cardiovascular disease risk. Circulation 121, 1356-1364.

23. Schulze MB, Manson JE, Ludwig DS et al. (2004) Sugarsweetened beverages, weight gain, and incidence of type 2 diabetes in young and middle-aged women. JAMA $\mathbf{2 9 2}$, 927-934.

24. Tordoff MG \& Alleva AM (1990) Effect of drinking soda sweetened with aspartame or high-fructose corn syrup on food intake and body weight. Am J Clin Nutr 51, 963-969.

25. Albala C, Vio F, Kain J et al. (2002) Nutrition transition in Chile: determinants and consequences. Public Health Nutr 5, 123-128.

26. Rivera JA, Barquera S, Campirano F et al. (2002) Epidemiological and nutritional transition in Mexico: rapid increase of non-communicable chronic diseases and obesity. Public Health Nutr 5, 113-122.

27. Boissonnet C, Schargrodsky H, Pellegrini F et al. (2011) Educational inequalities in obesity, abdominal obesity, and metabolic syndrome in seven Latin American cities: the CARMElA Study. Eur J Cardiovasc Prev Rehabil 18, 550-556.

28. Heidi Ullmann S, Buttenheim AM, Goldman N et al. (2011) Socioeconomic differences in obesity among Mexican adolescents. Int J Pediatr Obes 6, e373-e380.

29. Singh GK, Siahpush M, Hiatt RA et al. (2011) Dramatic increases in obesity and overweight prevalence and body mass index among ethnic-immigrant and social class groups in the United States, 1976-2008. J Community Health 36, 94-110.

30. Cuevas A, Alvarez V \& Olivos C (2009) The emerging obesity problem in Latin America. Expert Rev Cardiovasc Ther 7, 281-288.

31. Bermudez OI \& Tucker KL (2003) Trends in dietary patterns of Latin American populations. Cad Saude Publica 19, Suppl. 1, S87-S99.

32. Kain J, Vio F \& Albala C (2003) Obesity trends and determinant factors in Latin America. Cad Saude Publica 19, Suppl. 1, S77-S86.

33. Barrington DS, Baquero MC, Borrell LN et al. (2010) Racial/ ethnic disparities in obesity among US-born and foreignborn adults by sex and education. Obesity (Silver Spring) 18, 422-424.

34. Thompson FE, McNeel TS, Dowling EC et al. (2009) Interrelationships of added sugars intake, socioeconomic status, and race/ethnicity in adults in the United States: National Health Interview Survey, 2005. J Am Diet Assoc 109, 1376-1383. 